\title{
Entrevista com John Friedmann
}

\author{
Entrevista:
}

\section{Elisângela de Almeida Chiquito}

Arquiteta e Urbanista, pós-doutoranda no Instituto de Arquitetura e Urbanismo de São Carlos - IAU/USP, professora do Departamento de Planejamento Urbano da Escola de Arquitetura da Universidade Federal de Minas Gerais, Rua Paraíba 697, Funcionários, Belo Horizonte, MG, Brasil, CEP 30130-140, lisalmeida@ufmg.br

Tradução:

\section{Amanda Saba Ruggiero}

Revisão:

Elisângela de Almeida Chiquito

1 Em "Encounters with Development Planning", palestra sobre sua trajetória proferida em 24 de maio de 2009 em Londres, Friedmann deu o seguinte depoimento: " Durante semanas, eu vasculhei a biblioteca técnica da TVA procurando o Plano Diretor desta região, mas para meu espanto, não havia nada para ser encontrado. TVA era uma agência de planejamento com uma missão - sobre isso não havia dúvida. Mas o seu planejamento foi feito sem um plano regional abrangente. Eu estava atordoado por esta descoberta. Porque, se não havia nenhum plano, como era realizado o planejamento? Eu levaria décadas para encontrar a resposta desta pergunta, ou melhor, de como deveríamos pensar o planejamento."

20 livro a que se refere é a publicação de sua tese de doutorado: FRIEDMANN, J. The spatial structure of economic development in the Tennesse Valley. A study in Regional Planning. Chicago: Un. Of Chicago Press, 1955. ntrevista realizada em Vancouver, CA, em 8 de - junho de 2015.

Elisângela de Almeida Chiquito Inicialmente, gostaria de saber sobre o início de sua trajetória no planejamento regional, sobre sua primeira experiência prática junto ao Department of Regional Studies da Tennessee Valley Authority.

John Friedmann O meu trabalho na TVA foi entre o mestrado e o doutorado. Minha pesquisa de doutorado ocorreu enquanto trabalhei na TVA. Vou mostrar a dissertação que foi fruto disso. [Levantase, desce a escada para buscar os livros, retorna] Eu associei a geografia, economia e planejamento. Ainda não era claro o que era planejamento naquela época. ${ }^{1}$ E é uma pergunta que ainda permanece, uma das minhas questões favoritas: o que é planejamento?

A TVA foi o ponto inicial, a única coisa que eu sabia sobre desenvolvimento e planejamento regional. O conceito de desenvolvimento é muito novo. Em 1965 havia só uma publicação em desenvolvimento econômico regional e transformações culturais, foi publicado em 1963/64. O primeiro periódico acadêmico em desenvolvimento regional foi pela universidade de Chicago. Este foi um período interessante para mim, de encontrar um caminho para se pensar. Parecia quase como uma teoria secreta que teria de ser revelada, de como promover o desenvolvimento. Depois percebi que tudo estava errado! Mas foi de onde partimos. E claro, uma maneira de compreender isso foi através da história, da história comparativa. E outro modo foi experimentar isso pela prática profissional, e eu tive ambos.

A questão central era: o que é planejamento? Planejamento era visto como uma nova tecnologia, uma tecnologia que, quando você a juntava ao dinheiro, isso se transformava e gerava desenvolvimento. Claro que hoje sabemos que não é tão simples, mas era no que se acreditava naqueles tempos.

Bom, devo mostrar-lhe o livro², talvez fique mais claro. Este livro que você está vendo é resultado do que aprendi na Universidade de Chicago. Foi uma tentativa de reinterpretar a experiência de planejamento do Tennessee Valley Authority, do ponto de vista do planejamento dos recursos, que significava capturar a força do rio para navegação, controle de enchentes, recreação e uso da terra. Esses quatro elementos, juntamente com o manejo de florestas, aprender quais seriam as melhores culturas que poderiam crescer nas planícies e nas zonas altas, todas estas coisas juntas formavam a ideia de desenvolvimento integrado de recursos. E isso tudo conectado à engrenagem do desenvolvimento.

Inicialmente, a geração de energia era distribuída para cooperativas, que compravam energia em grande escala e distribuía aos membros cooperados, era um ciclo. E a TVA tinha o monopólio da energia, 


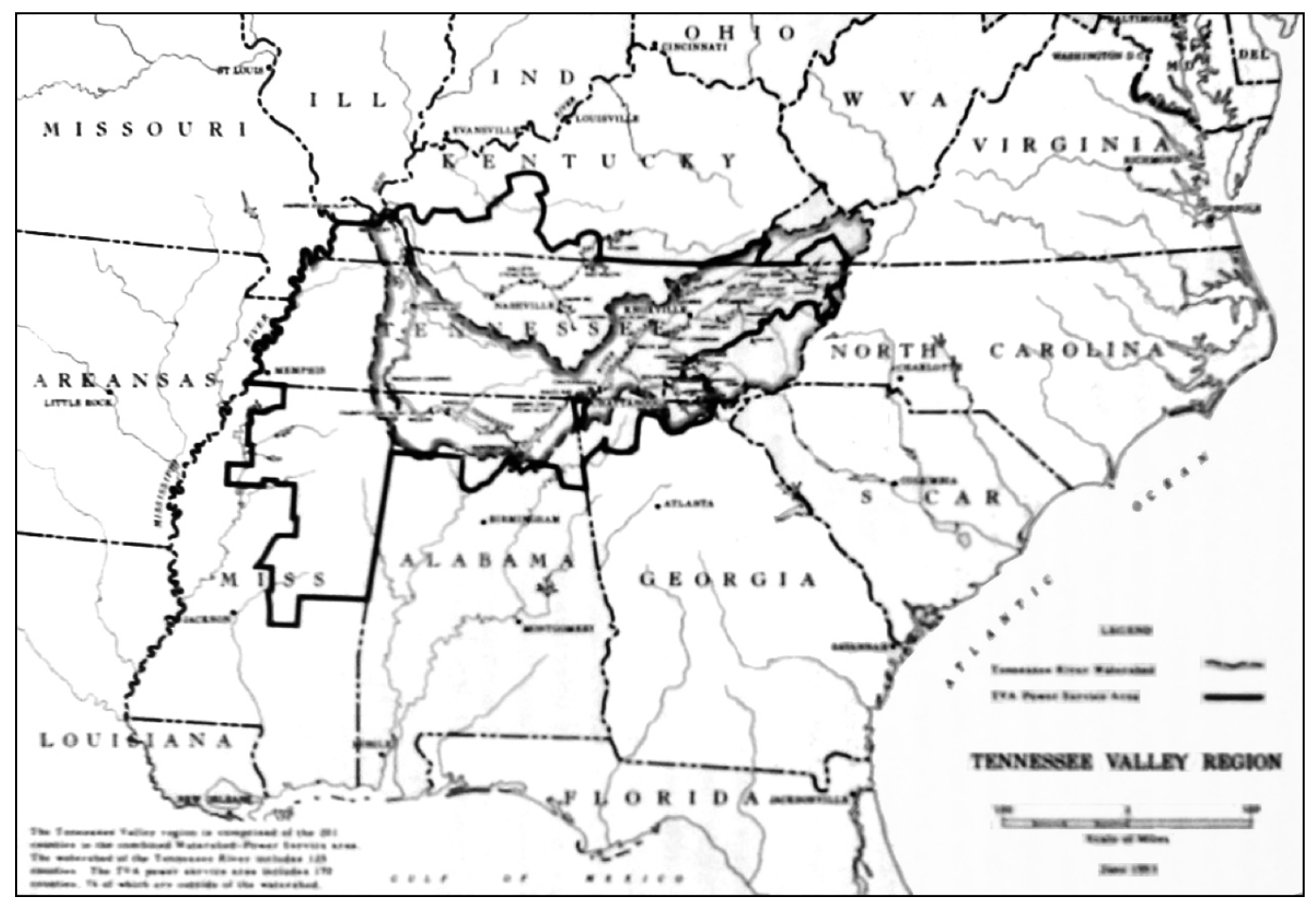

Figura 1: Sobreposição da região do Vale do Tennesse e da "Power Service Area" da TVA. Fonte: Friedmann (1955).

3 A região do Vale do Tennesse possuía, em 1950, apenas duas cidades de porte médio, Knoxville com 124.769 habitantes e Chattanooga com 131.041 habitantes. As demais eram cidades com menos de 30 mil habitantes.

40 artigo a que se refere é "Locational Aspects of Economic Development" publicado no Journal of Land Economics em 1956 não só ao longo do vale do rio, mas no que era chamado "Power Service Area", que era maior do que a área do vale do rio Tennessee (aponta à figura do vale em seu livro), pois era conectada às cidades. Então, o rio em si tinha no máximo, duas cidades médias, que eram centros de energia registrados. $^{3}$ [ver Figura 1 ] Mas o que eu queria ressaltar é que o desenvolvimento econômico requer que as cidades tenham um papel ativo como lugar. Minha tese também gerou alguns artigos. Um deles está relacionado com a localização de indústrias, onde uso o conceito de aspectos locacionais do desenvolvimento econômico. ${ }^{4}$ Quando eu estava na Bahia produzimos a tradução deste artigo, e esta foi uma das coisas que fiz no Brasil.

E.A.C. Depois de trabalhar na TVA e finalizar o doutorado você foi para o Brasil, em 1955. Como isso aconteceu?

J.F. Bem, quando me foi dada a oportunidade de ir para o Brasil pela USAID [United States Agency for International Development] eu não sabia nada de português e não sabia nada sobre o Brasil. E tive que aprender rapidamente, e uma das primeiras coisas era a língua, tive que aprender o português. E, inicialmente, tive um ótimo intérprete, um brasileiro, poeta, chamado Mário Faustino, do Piauí. Ele vinha de uma família com onze irmãos - naquela época as pessoas tinham bastantes filhos! Mas Mário tinha um ótimo inglês, ele havia passado um tempo nos Estados Unidos, tinha interesse em poesia moderna, em Ezra Pound. Tivemos uma boa relação, ele era um pouco mais novo, tivemos uma grande amizade.

Então fomos para a Amazônia. Eu lecionei um Curso de Teoria do Planejamento em Belém do Pará. Os alunos eram da Superintendência do Plano de Valorização Econômica da Amazônia (SPVEA), onde o curso era oferecido. Tinham acabado de comprar dois navios novos para turistas. Então pegamos estes barcos com os alunos e fomos numa expedição de duas semanas. Foi uma experiência interessante. Havia muito a ser visto quando estávamos em terra, mas na água você não consegue ver muita coisa... [risos]. Dei o Curso de Teoria do Planejamento e mais tarde eu desenvolvi uma serie de palestras que foram publicadas em um livro pela Fundação Getúlio Vargas. Eu estava construindo minhas reflexões sobre planejamento, pois todo mundo estava pensando 
Figura 2: Capa do livro "The Spatial Structure od Economic Development. Fonte: acervo da autora. sobre isso naquele momento. Você sabe disso, escreveu sobre o Padre Lebret, que também foi uma influência no Brasil naquele período. Mas todo mundo estava procurando pela chave de ouro de algo que estava trancado. A questão era como o planejamento poderia levar ao desenvolvimento. Foi minha tentativa de contribuição ao fazer essas palestras.

E.A.C. Quais os principais aspectos da sua experiência na TVA que você levou para sua atuação no SPVEA?

J.F. A experiência na TVA não foi necessariamente relevante para a Amazônia. Foram experiências bem distintas. Bem...talvez não. Por exemplo, este livro é sobre energia. [aponta para imagem na capa do livro - ver Figura 2] Aqui é energia elétrica e aqui são os padrões das linhas de tráfego do fluxo de energia, os veículos, mas estas são as cidades e os nós interconectados. Eu defino o que seria o Vale do Tennessee de forma geral, como um grande tubo extenso, e esta aqui é uma rede de cidades, uma concepção espacial completamente diferente.
Na Amazônia era tudo bem separado, a energia elétrica, a navegação, e havia somente duas cidades significativas, Belém do Pará e Manaus. São diferentes do ponto de vista da geografia humana e da geografia física, totalmente diferente. A geografia humana parece mais com este. E é claro, isso é o transporte de energia, uma rede que flui, não somente objetos físicos, materiais. Algumas coisas imateriais são reais, mas imateriais, você não vê a eletricidade. Você na verdade não enxerga estas redes, você tem que construí-las para torna-las visíveis.

E.A.C. Como se deu o seu contrato com o Brasil?

J.F. A Escola Brasileira de Administração Publica (EBAP) que me contratou para o curso de planejamento regional. Eu fui um dos professores do curso. Era um programa de 16 semanas, mais ou menos. O curso foi desenvolvido para os funcionários da Superintendência, havia pessoas de várias áreas do Governo, da universidade, e militares. A EBAP entrou em contato com a embaixada Americana,

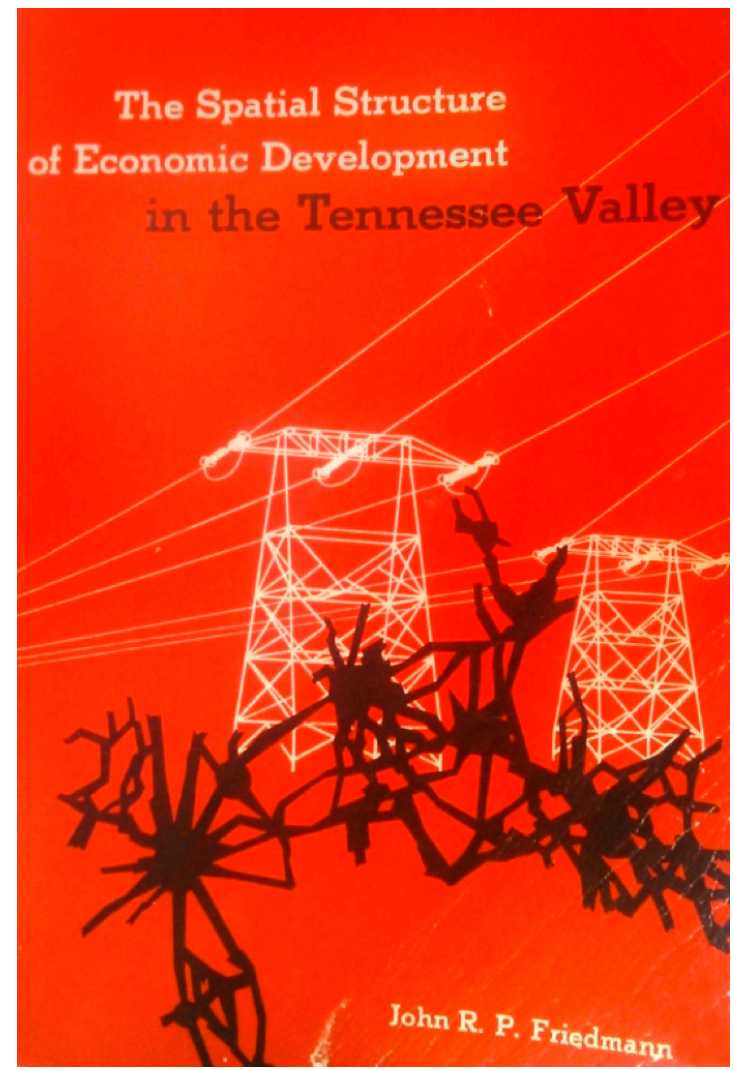


5 Harvey Perloff foi docente na Universidade de Chicago entre 1947 e 1955. Durante o governo Kennedy foi consultor sobre América Latina e representante dos Estados Unidos no Comitê dos Nove do Programa Aliança para o Progresso. Em 1968, foi nomeado diretor da Escola de Arquitetura e Planejamento Urbano da UCLA. Perloff foi o grande incentivador para atuação de Friedmann na América Latina e principal responsável pelo seu ingresso como docente na UCLA em 1969 . com a USAID, e havia um cargo. Eles estavam procurando um expert em planejamento regional. E eu fui o primeiro graduado em planejamento regional. Meu professor orientador, o professor Harvey Perloff ${ }^{5}$, ficou sabendo disso e me disse: - Vá conferir! Naquele momento eu estava procurando trabalho. Tinha acabado de concluir meu doutorado e estava passeando pela universidade até alguma coisa aparecer. Então surgiu o trabalho.

E.A.C. Você teve uma indicação?

J.F. Não. Eu fui ao Rio de Janeiro para uma primeira entrevista, foi o primeiro contato. Depois eu levei minha esposa. Naquele momento assinei um contrato para um trabalho específico. No meu caso - claro que pode parecer diferente para vocês - mas no meu ponto de vista era: estou aprendendo aqui! Era para eu ser o expert, mas parecia um tipo de brincadeira, eu estava mais aprendendo do que sendo um expert. Minha visão é que estava constantemente desenvolvendo minhas próprias ideias, meu ponto de vista sobre o planejamento regional. E isso começou a se reunir na publicação sobre a Venezuela.

Depois que acabamos em Belém, fomos ao Rio de Janeiro e fiquei envolvido com a Escola (EBAP) e com a escrita e a tradução deste livro [aponta o livro "Introdução ao planejamento regional"], aguardando um novo contrato. E depois um novo contrato apareceu em poucos meses, por intermédio de Rômulo Almeida. Ele era o diretor responsável, não me lembro bem o cargo que ocupava no desenvolvimento econômico da Bahia. Ele me levou para a Universidade e lá havia o Instituto de Economia e Finanças da Bahia. Era uma instituição que estava obsoleta e sem produzir, não estava funcionando. E ele propôs: vamos fazer uma coisa nova, criar algo novo, uma escola ou instituto de planejamento do espaço ou territorial - diferentes nomes para a mesma coisa. Foi o que fizemos juntos. Havia um novo diretor na universidade e ele apoiou a ideia de criar um novo centro e disponibilizou recursos para isso. E meu primeiro trabalho era definir um diretor para este centro, que tinha que ser brasileiro. Então um dos meus alunos no curso de Belém, Armando Dias Mendes, falecido há poucos anos, foi convidado pela universidade, por minha indicação. Ele era do Pará, era um advogado e não economista. Enquanto eu estava lá, tudo correu bem. Mas depois ele não conseguiu se integrar na sociedade bahiana... Ele ficou no cargo um ano e meio, e então o centro fechou. Demos um curso de mestrado, para pessoas com diploma de graduação. O Instituto se manteve por alguns anos, e depois com o golpe militar alguns alunos saíram do país e mudaram de trabalho. As coisas começavam a mudar (...) seria interessante pensar como isso teria continuado.

A USAID, na verdade, não sabia o que eu estava fazendo e não estava interessada nisso. Havia também outra pessoa, meu chefe na TVA, Stefan Robock, era um consultor do Banco do Nordeste do Brasil, em Fortaleza, eles também tinham um programa de desenvolvimento regional. Isso era o que eles (USAID) estavam financiando. Tinham poder e dinheiro. A universidade era apenas a universidade enquanto eles estavam realizando projetos. Então me disseram: já temos alguém em planejamento regional. E interromperam a ajuda financeira. O diretor Armando Mendes tinha voltado para Belém, e depois se tornou presidente do Banco da Amazônia. Ele era um planejador regional e depois trabalhou no Banco de Desenvolvimento da Amazônia, similar ao Banco do Desenvolvimento do Nordeste. Ele se tornou o presidente do banco da Amazônia e depois ele criou um instituto de pesquisa. Ele realmente deu um salto, avançou em se tornar uma pessoa orientada para o desenvolvimento, é bem interessante esta conexão. E ele era realmente um cidadão do Pará, um patriota da Amazônia. Tinha a intenção de promover o desenvolvimento da Amazônia, mas em seguida veio o golpe.

E.A.C. O que levou da experiência no Brasil para o MIT (Massachusetts Institute of Technology)?

J.F. Eu fui o primeiro especialista sobre o desenvolvimento e o planejamento regional, muito diferente de planejamento urbano, que é muito mais ligado ao desenho. No meu caso era uma orientação mais direcionada às políticas de desenvolvimento. Quando fui para o MIT, após dois anos na Coreia, meu trabalho foi de ensinar o planejamento regional, este foi meu trabalho. Eu tinha o conhecimento adquirido no Brasil e na Coreia. Eu não fiz planejamento regional na Coreia, foi mais política de desenvolvimento regional. Não ficou definido muito bem o meu trabalho lá, estava sempre aprendendo e pensando sobre as coisas. Mas quando fui para o MIT, tive que ser mais sistemático com meus pensamentos. 
6 Editado juntamente com Willian Alonso e publicado em 1964.

7FRIEDMANN, J. (1975) The spatial organization of power in the development of urban systems. In: FRIEDMANN, J.; ALONSO, W. (eds.) Regional Policy. Readings in theory and application. Cambridge, MA: MIT Press. pp. 266-304.
Então me deixe mostrar os livros publicados. Este primeiro se chama Regional Policy. Readings in theory and application - a primeira edição se chama Regional Development and Planning - A Reader. ${ }^{6} \mathrm{Eu}$ escrevi este artigo, Spatial Organization of Power and Urban Systems ${ }^{7}$. Houve diferentes contribuições aqui. Este era o estado do pensamento da época. E há algo aqui, um capítulo em especial, que é um ensaio bibliográfico intitulado Regional development planning: the progress of a decade, que dá um panorama. Foi minha tentativa de cobrir a literatura existente, de estabelecer o planejamento regional como uma especialização dentro do planejamento urbano e regional. No momento que foi feito a segunda edição do livro, a ideia de desenvolvimento regional havia acabado. Havia o neoliberalismo, a partir de 1975, de 1980, naquele período havia o estado vazio, o desmanche do poder do estado e a força do capital privado.

E.A.C. Fale um pouco sobre sua atuação na Venezuela?

J.F. No MIT teve o estudo de caso do desenvolvimento na Venezuela. Eu lecionava no MIT, e lá eles tinham um projeto em conjunto com a Universidade de Harvard, um convênio com a cidade de Guayana e parte do acordo com o governo da Venezuela. Eles providenciaram assistência técnica, através da Corporación Venezolana de Guayana (CVG), e fizemos pesquisa. Eu fui como pesquisador, esta foi uma opção minha.

Eu escrevi sobre a Venezuela, fiz uma pesquisa e dei algumas palestras em um centro de desenvolvimento, o CENDES, que era liderado por um economista chileno que depois me chamou para o trabalho no Chile. Seu nome era Jorge Ahumada. Ele faleceu, infelizmente, mas foi o diretor do CENDES. Eu tentava dar sentido a algumas informações, criando diagramas, e depois fiz uma série de mapas, acho que os mapas são bem interessantes. Dê uma olhada. A ideia era escrever sobre o que você esta escrevendo, sobre um plano nacional de desenvolvimento regional. Foi sobre isso o trabalho na Venezuela.

E.A.C. A iniciativa da pesquisa partiu da Venezuela ou das universidades americanas?

J.F. Isto foi Rómulo Betancourt, um presidente liberal, talvez o melhor presidente que a Venezuela teve. Ele era um novo democrata após o governo de Marcos Pérez Jimenez, que foi ditador por 20 anos. Ele entrou no lugar do ditador Jimenez e começou um novo regime, começou a usar o dinheiro do petróleo que a Venezuela tinha para industrializar o país, não somente exportar o petróleo, mas agregar valor. Eles tinham uma visão de desenvolver o país. Uma cidade industrial, chamada Guayana, ficava na confluência de dois rios, Caroní e Orinoco [mostra livros e mapas]. Foi uma tentativa de ser analítico.

Neste projeto havia estudantes de Harvard. Eram arquitetos que ajudaram a fazer estes mapas. Este era o outro rio, o rio Orinoco, havia um espaço vago no início do delta, e nesta região queriam criar a indústria do aço, e enfim criar um novo polo de desenvolvimento regional. Este novo polo de energia descentralizaria a região de Caracas. Outro polo era a cidade de Barquisimeto, um local bem pobre.

Eles criaram a Corporación Venezolana de Guayana e colocaram um militar para dirigir, Rafael Alfonzo Ravard, engenheiro do MIT, que fez o contato entre a Universidade de Harvard e o MIT, para fazer pesquisa e levar o conhecimento, levar energia do norte e desenvolver as outras cidades e partes do país. Um dos coordenadores da pesquisa, Lloyd Rodwin, um dos diretores do MIT e meu chefe direto na pesquisa, propôs fazer a pesquisa numa determinada região, mas eu não concordei, não estava interessado nessa região, eu estava interessado estudar a política regional, e então tivemos uma grande desavença. $\mathrm{E}$ então eu deixei o MIT e fui para o Chile, mas produzi este livro. [aponta para o livro Regional development policy: a case study of Venezuela]

E.A.C. Como foi sua aproximação com Walter Isard e a Regional Science Association?

J.F. A Regional Science Association foi criada por Walter Isard, um economista, preocupado com questões de localização. Foi interessante quando a geografia era dominada por este pensamento. Isard começou com um programa de doutorado em Regional Science, na Universidade de Pensilvânia. William Alonso foi aluno de Isard, o primeiro orientando dele. Depois Isard tentou mudar para Cambridge, pois havia mais prestigio em Harvard, mas a universidade não teve muito interesse. Não havia muito interesse em geografia 
pela universidade de Harvard. Ele foi para o Departament of Lansdcape Architecture, mas não conseguiu se firmar, estabelecer seu espaço de atuação em Harvard. A geografia mudou, ele se aposentou e foi lecionar na Cornell University. Mas a Regional Science ficou instituída. É um movimento pequeno que permanece até hoje, mas não tão interessante, pois não teve uma personalidade marcante para se desenvolver. Em parte porque a geografia se ampliou demais, e também porque a teoria se baseava obsessivamente em modelos quantitativos, e não muito em assuntos de políticas, enquanto que a maioria das pessoas no mundo estava mais interessada em política regional, e não em ciência regional. Então a ciência regional não tinha muito a oferecer senão modelos, não era muito atraente para a política. Foi um momento.

E.A.C. No livro Territory and function, de 1981, você traça um panorama histórico do planejamento regional nos Estados Unidos, enfatizando as concepções teóricas e os deslocamentos que elas sofrem ao longo do tempo. Na terceira parte você trata da "crise do desenvolvimento". Você poderia falar a respeito?

J.F. Naquele momento eu estava envolvido em assuntos de planejamento regional. Agora isso mudou, fala-se em desenvolvimento metropolitano e urbano, ficou mais manejável. Ao pensar em regiões metropolitanas podemos ver a relação com o ambiente de forma mais direta. Quando se pensava em políticas nacionais naquele momento, pensava-se na alocação de recursos pelo estado para promover o desenvolvimento. Hoje se pensa de outra maneira, em como atrair investimento privado. É um modo completamente diferente.

E.A.C. Parece que durante os anos 1970 houve uma reorientação de seu trabalho...

J.F. Bem...no meio dos anos 1970 tivemos uma nova revolução, neoliberal, uma revolução diferente, mas com grandes consequências. E eu mudei minha perspectiva de vida e decidi que o Planejamento Regional não era para mim (...) e desisti do planejamento regional e do apoio do estado ao planejamento (...), eu sei que precisamos do Estado, não sou um anarquista. Mas fiquei mais interessado em organizações locais, pequenos espaços, comunidades, planejamento de unidades de vizinhança comunitárias, movimentos sociais, sociedade civil.

E depois mudei minha pesquisa de ambiente geográfico, da América Latina para a China. Na China pode se ver por um lado um grande sucesso em termos econômicos, como o GDP (Gross Domestic Products), uma medida usual per capita. Por um lado o crescimento deste fator, e por outro sua relação com o declínio da qualidade ambiental. Hoje as coisas são mais complexas.

E.A.C. Você acha que as políticas nacionais de desenvolvimento tinham uma utopia que foi substituída pelo dinheiro?

J.F. É uma interpretação política (...) se você conversar com as pessoas na China o que importa é somente o dinheiro. Não somente, também tem o poder nacional em um mundo global. A China não se sustenta por si com seus próprios recursos, nem o Canadá, EUA. Compramos da Ásia, os alimentos vêm de todo lugar. Não produzimos muito. Temos serviço, mas nosso consumo em geral vem de algum lugar. É muito complicado, não sei... Não sabemos o que vai acontecer, nem um nem outro, mas algo entre, talvez!

E.A.C. Então esta mudança para você foi uma desilusão?

J.F. Para mim foi. Eu me divorciei de um modo pessoal de pensar e inclusive no relacionamento com as pessoas e, em particular, com minha esposa naquele momento. E depois fiquei sozinho por dez anos e depois me casei novamente. Mas minha orientação política sobre planejamento mudou para uma prática social, que é mais o que acontece no nível da sociedade civil, e acho que é a única esperança que temos. Recentemente, no livro Insurgencies, publiquei um conjunto de artigos que escrevi desde 1973 até os dias atuais, mas tem uma introdução que tento explicar teoricamente esta minha mudança, é um textbook.

No livro "Planning in the public domain" eu trato da mobilização social, utopismo, anarquismo, materialismo histórico. Os utopistas dizem: o futuro é agora, você cria uma sociedade alternativa agora. O anarquismo social é a imanência de 
uma boa sociedade que pode ser alcançada por esta reestruturação completa, pela própria governança, e a possibilidade do aprendizado social é imediata. E o materialismo histórico explora as interpretações internas da sociedade capitalista. Foi minha tentativa de tratar o assunto em seu conjunto, conectado de movimentos, mas internamente, com formatos diferentes, com diferentes características. Eu fiz um estudo histórico, sobre os tipos de movimentos sociais, que deve ser expandido, e isso não foi feito. Isso deve ser realizado, alguém tem que fazer uma pesquisa sobre isso.

Geralmente os movimentos sociais sempre brigam entre si. A esquerda nunca se une, enquanto a aliança é uma estratégia política. Mas quando você pensa sobre os movimentos de ocupação, como Ocuppy Wall Street, são geralmente o tipo de movimentos populares. Há presença do anarquismo lá visivelmente, mas muitos simpatizantes, adeptos ao pensamento utópico, e claro, marxistas estão sempre lá, trotskistas, stalinistas, estão juntos em alguns momentos históricos.

Então a tradição da mobilização social, nós precisamos repensar o que precisamos do planejamento, e eu estava acostumado a pensar o planejamento pelo Estado, mas por outro lado há as práticas sociais, este talvez seja o melhor termo para definir isso, eu não elaborei isso, mas creio que é algo que devemos pensar mais sobre. É uma fase do planejamento a prática social.

E então, não podemos mais planejar o conjunto, mas podemos pensar as partes. Planejar significa transformar, é uma teoria da transformação, e isso precisa ser elaborado, uma real transformação social. E eu tenho alguma ideia sobre isso, de qualquer modo. Então acho que você deve fazer isso, é nova e tem 50 anos para trabalhar ainda.

E.A.C. Quais são seus vínculos atuais com o Brasil? Seus interesses?

J.F. Eu mantenho meu interesse pelo Brasil, nos movimentos sociais, no movimento sem-terra, e toda questão da democracia participativa. Acho que o Brasil é um tipo de líder, é um dos lugares do mundo que acredito que há uma certa esperança. Se você olha para a China, Índia, e
Oriente Médio, sem mencionar África, não há muito otimismo para estes locais, de modo geral. Então você olha para algumas pequenas luzes, é fácil chegar a conclusões.

Na ditadura de Pinochet, no Chile, havia muita criatividade acontecendo no país. Eu levei isso a sério e investi certa esperança nesses movimentos. O capitalismo e sua força são muito poderosos, é muito difícil se defender do capitalismo. E não temos nenhum outro sistema em que acreditar sem ser o capitalismo. Mas acho que estaremos forcados a mudar, pois temos problemas ecológicos para se resolver, ambientais. E no fim estamos nos destruindo uns aos outros para manter os últimos recursos. É o que esta acontecendo na Rússia, China, África, USA, e a relação de força no oriente médio, estão se destruindo. Então não sei (...) mas quando você ouve as pessoas falarem de participação, como nas comissões de bacia regional, como o presidente que foi do Brasil, Lula, que trouxe grandes mudanças sociais (...) no geral acho que coisas boas acontecem no Brasil. Não estou diretamente envolvido mas tenho acompanhado de fora.

\section{Referências bibliográficas}

FRIEDMANN, J. Aspectos locacionais do desenvolvimento econômico. Série IV, Caderno I. Salvador: Universidade da Bahia, 1957.

. Globalization and the Emerging Culture of Planning. Progress in Planning, 64 (3), 2005, pp.183-234.

La estratégia de los polos de crescimento como instrumento de la política de desarollo. Revista de la Sociedade Interamericana de Planificación, vol. III, n $^{\circ}$ 9-10, 1969.

Planning in the Public Domain: From Knowledge to Action. Princeton: Princeton University Press, 1987.

Regional development policy: a case study of Venezuela. Cambridge, MA: MIT Press, 1966.

Retracking America: A Theory of Transactive Planning. New York: Anchor Press, 1973.

The spatial structure of economic development in the Tennesse Valley. A study in Regional Planning. Chicago: Un. Of Chicago Press, 1955.

Urban and Regional Development in Chile: A Case Study of Innovative Planning. Los Angeles: UCLA Library, 1969.

FRIEDMANN, J. R. P. Introdução ao planejamento regional - com referência especial à região amazônica. Rio de Janeiro: FGV, 1960. 
FRIEDMANN, J.; ALONSO, W. (1975) Regional Policy. Readings in theory and application. Cambridge, MA: MIT Press.

FRIEDMANN, J.; ALONSO, W. (eds.) Regional Policy. Readings in theory and application. Cambridge, MA: MIT Press. pp. xv-xxi.

FRIEDMANN, J.; LEAL, J. População e mão de obra na Bahia. Coleção Cadernos de Desenvolvimento Econômico. Série I, Caderno I. Salvador: Universidade da Bahia, 1957.

Figura 3: John Friedmann. Fonte: fotografia de Elisângela de Almeida Chiquito.
FRIEDMANN, J.; WEAVER, C. Territory and function. The evolution of Regional Planning. London: Edward Arnold, 1979.

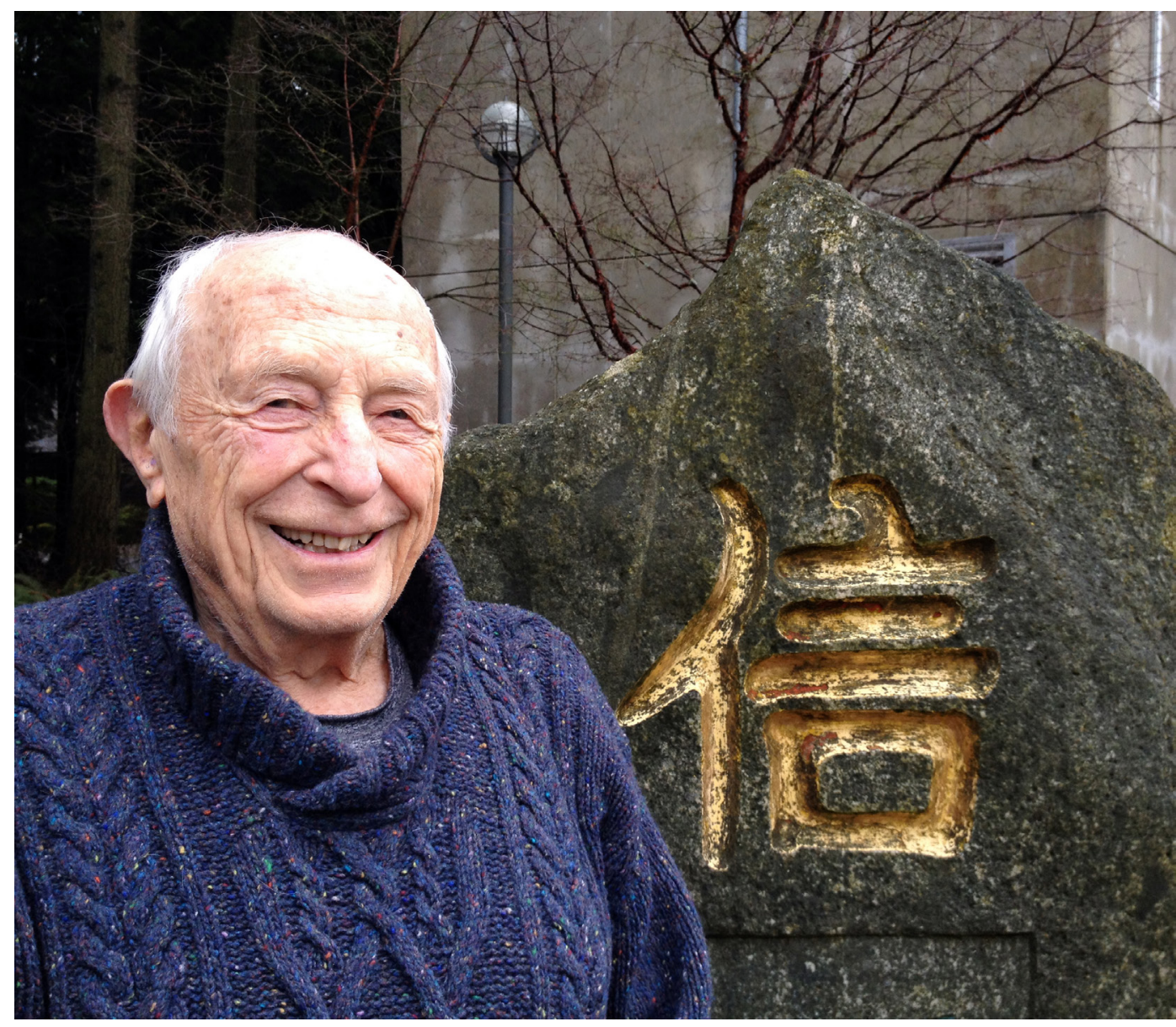

